MR ANDERS GRANHOLM (Orcid ID : 0000-0001-5799-7655)

MR CARL THOMAS ANTHON (Orcid ID : 0000-0001-7740-700X)

DR SØREN MARKER (Orcid ID : 0000-0003-3602-4541)

MISS TINE SYLVEST MEYHOFF (Orcid ID : 0000-0002-1840-1596)

PROFESSOR ANDERS PERNER (Orcid ID : 0000-0002-4668-0123)

DR MORTEN HYLANDER MØLLER (Orcid ID : 0000-0002-6378-9673)

Article type : Clinical investigation

\title{
Time to onset of gastrointestinal bleeding in the SUP-ICU trial: a preplanned substudy
}

Anders Granholm ${ }^{1}$, Theis Lange ${ }^{2,3,4}$, Carl Thomas Anthon ${ }^{1}$, Søren Marker ${ }^{1,2}$, Mette Krag $^{1,2}$, Tine Sylvest Meyhoff ${ }^{1,2}$, Matt P. Wise ${ }^{5}$, Mark Borthwick ${ }^{6}$, Stepani Bendel ${ }^{7}$, Frederik Keus $^{8}$, Anne Berit Guttormsen ${ }^{9}$, Joerg C. Schefold ${ }^{10}$, Jørn Wetterslev ${ }^{2,11}$, Anders Perner ${ }^{1,2}$, Morten Hylander Møller ${ }^{1,2}$

${ }^{1}$ Department of Intensive Care, Copenhagen University Hospital - Rigshospitalet, Copenhagen, Denmark

${ }^{2}$ Centre for Research in Intensive Care (CRIC), Copenhagen, Denmark

${ }^{3}$ Department of Public Health, Section of Biostatistics, University of Copenhagen, Copenhagen, Denmark

${ }^{4}$ Center for Statistical Science, Peking University, Beijing, China

${ }^{5}$ Department of Adult Critical Care, University Hospital of Wales, Cardiff, United Kingdom

${ }^{6}$ Pharmacy Department, Oxford University Hospitals NHS Foundation Trust, Oxford, United Kingdom

${ }^{7}$ Department of Intensive Care Medicine, Kuopio University Hospital, Kuopio,

Finland

${ }^{8}$ Department of Critical Care, University Medical Center Groningen, University of Groningen, Groningen, The Netherlands

${ }^{9}$ Department of Anaesthesia and Intensive Care, Haukeland University Hospital and Department of Clinical Medicine, UiB, Bergen, Norway

${ }^{10}$ Department of Intensive Care Medicine, Inselspital, University of Bern, Bern, Switzerland

${ }^{11}$ Copenhagen Trial Unit, Centre for Clinical Intervention Research, Copenhagen University Hospital, Rigshospitalet, Copenhagen, Denmark

This article has been accepted for publication and undergone full peer review but has not been through the copyediting, typesetting, pagination and proofreading process, which may lead to differences between this version and the Version of Record. Please cite this article as doi: 10.1111/aas.13459

This article is protected by copyright. All rights reserved. 


\section{Corresponding author:}

Anders Granholm, B.Sc.

Department of Intensive Care 4131, Copenhagen University Hospital -

Rigshospitalet

Blegdamsvej 9, DK-2100 Copenhagen, Denmark

E-mail: andersgran@gmail.com

Short title: Time to Gl bleeding in the SUP-ICU trial

\section{Conflicts of interest:}

All authors were involved in the conduct of the SUP-ICU trial.

The Department of Intensive Care at Rigshospitalet receives support for other research projects from Ferring Pharmaceuticals, Denmark, and the Novo Nordisk Foundation, Denmark.

Dr. Schefold reports grants from Orion Pharma, Abbott Nutrition International, B. Braun Medical AG, CSEM AG, Edwards Lifesciences Services GmbH, Kenta Biotech Ltd, Maquet Critical Care AB, Omnicare Clinical Research AG, Nestle, Pierre Fabre Pharma AG, Pfizer, Bard Medica S.A., Abbott AG, Anandic Medical Systems, Pan Gas AG Healthcare, Bracco, Hamilton Medical AG, Fresenius Kabi, Getinge Group Maquet AG, Dräger AG, Teleflex Medical GmbH, Glaxo Smith Kline, Merck Sharp and Dohme AG, Eli Lilly and Company, Baxter, Astellas, Astra Zeneca, CSL Behring, Novartis, Covidien, and Nycomed outside the submitted work. The money went into departmental funds. No personal financial gain applied.

The other authors declare no direct conflicts of interests.

\section{Acknowledgements:}

The authors thank everybody involved in the SUP-ICU trial: research staff and investigators, clinical staff, patients and their relatives.

The SUP-ICU trial was funded by Innovation Fund Denmark (4108-00011A) and supported by Rigshospitalet, the Capital Region of Denmark, the Regions of Denmark, the Scandinavian Society of Anaesthesiology and Intensive Care Medicine, Ehrenreich's Foundation, Aase and Ejnar Danielsens Foundation, the Danish Society of Anaesthesiology and Intensive Care Medicine, the Danish Medical Association and the European Society of Intensive Care Medicine. None of the funders had any influence on any aspects of this substudy.

\section{Authors' contributions:}

A.G. wrote the first draft. A.G. and T.L. conducted all statistical analyses. S.M. and M.K. were responsible for the SUP-ICU trial database. A.G., T.L., J.W. and M.H.M. drafted the protocol and statistical analysis plan. All authors contributed substantially to the SUP-ICU trial, the study protocol, this manuscript and approved the final version. 


\section{Abstract}

\section{Background}

The aetiology and risk factors for clinically important gastrointestinal bleeding (CIB) in adult ICU patients may differ according to onset of CIB, which could affect the balance between benefits and harms of stress ulcer prophylaxis (SUP).

\section{Methods}

We assessed the time to CIB in the Stress Ulcer Prophylaxis in the Intensive Care Unit (SUP-ICU) trial. We assessed if associations between baseline characteristics including allocation to SUP and CIB changed during time in the ICU, specifically in the later (after day two) compared to the earlier (first two days) period, using Cox models adjusted for SAPS II and allocation to SUP. Additionally, we described baseline characteristics and CIB episodes stratified by earlier/later/no CIB and 90day mortality status.

\section{Results}

CIB occurred in 110/3291 (3.3\%) patients after a median of 6 (interquartile range 213) days; $25.5 \%$ of the episodes occurred early. Higher SAPS II was consistently associated with increased risk of CIB (hazard ratio (HR) 1.03, 95\% confidence interval $(\mathrm{Cl}) 1.01-1.05$ in the earlier period vs $\mathrm{HR} 1.02,95 \% \mathrm{Cl} 1.01-1.03$ in the later period; $P=0.37$ ); university hospital admission was associated with decreased risk of earlier CIB (HR 0.30, 95\% Cl 0.14-0.63); this significantly increased in the later period (to HR $0.85,95 \% \mathrm{Cl} 0.53-1.37 ; P=0.02$ ). Patients with later compared to earlier $\mathrm{CIB}$ received more transfusions and had more diagnostic/therapeutic procedures for CIB.

\section{Conclusions}

CIB mostly occurred more than two days after randomisation. University hospital admission was associated with significantly decreased risk of CIB in the earlier period only.

ClinicalTrials.gov registration: NCT02467621.

\section{Editorial Comment}

When gastrointestinal bleeding is likely to occur as a complication in critically ill patients is unclear. In this secondary analysis from this large trial trial of stress ulcer prophylaxis, the median time to bleeding detection was 6 days, and higher SAPS-II scores were associated with higher risk for bleeding. 


\section{Introduction}

Intensive care unit (ICU) patients are at risk for stress-related gastrointestinal (GI) bleeding, which is associated with adverse outcomes including death. ${ }^{1}$ In the Stress Ulcer Prophylaxis in the Intensive Care Unit (SUP-ICU) inception cohort study conducted in 2013-2014, most ICU patients received stress ulcer prophylaxis (SUP) with acid suppressants, ${ }^{2}$ as recommended in international guidelines. ${ }^{3}$

Clinically important GI bleeding (CIB) occurs in 2-3\% of ICU patients, ${ }^{2}$ and stress ulcers are confirmed as the source of bleeding in less than half of critically ill patients with Gl bleeding undergoing endoscopy. ${ }^{4}$

It has been suggested that SUP may increase the risk of nosocomial pneumonia, Clostridium difficile infections and cardiovascular events. ${ }^{5,6}$ In a recent systematic review with meta-analysis and trial sequential analysis, SUP did not affect mortality. ${ }^{7}$ SUP reduced overt GI bleeding and there was indication of, but not firm evidence for, a reduction in $\mathrm{CIB} .^{7}$ Additionally, the effects on adverse events, pneumonia, Clostridium difficile infections and myocardial ischemia were uncertain. ${ }^{7}$

In the SUP-ICU inception cohort study, approximately half of the patients with CIB had onset of bleeding within the first two days in the ICU. ${ }^{2}$ The aetiology and risk factors for earlier vs later Gl bleeding may differ, ${ }^{8}$ and differences in patients with earlier vs later CIB may affect the balance between benefits and harms of SUP.

The primary objectives of this study were to assess the time to CIB and whether the associations between use of SUP and baseline characteristics with CIB changed over time, specifically, in the earlier (first two days) vs later (day three or later) period. Secondary objectives were to describe baseline and bleeding episode characteristics in patients with earlier vs later CIB. We hypothesised that time to CIB would be similar to the SUP-ICU inception cohort study, that associations between allocation to SUP and baseline characteristics could change over time, and that outcomes and interventions used in patients with earlier vs later CIB could differ.

\section{Methods}

\section{Study design, population and approvals}

This preplanned, exploratory substudy of the SUP-ICU randomised clinical trial ${ }^{9}$ (RCT) was conducted according to a protocol and statistical analysis plan finalised before the closure of the trial database on 21 March 2018 and subsequently published. ${ }^{10}$ The manuscript was prepared according to the Strengthening the Reporting of Observational Studies in Epidemiology (STROBE) statement. ${ }^{11}$ Additional methodological details and the completed STROBE checklist are presented in the supplement. 
The SUP-ICU trial was an investigator-initiated, international, blinded, parallel-group RCT, which randomised adult patients acutely admitted to an ICU with one or more risk factors for Gl bleeding to either $40 \mathrm{mg}$ pantoprazole (SUP) or matching placebo intravenously once daily during ICU admission for a maximum of 90 days. ${ }^{9}$

The main exclusion criteria were previous Gl bleeding during the index hospitalisation, ongoing treatment with acid suppressants, or contraindications to pantoprazole; detailed enrolment criteria are available in the supplement and elsewhere. ${ }^{9,12,13}$ Patients were enrolled from 4 January 2016 through 22 October 2017, and all patients included in the primary analyses of the SUP-ICU trial were included in this substudy.

The SUP-ICU trial was approved by the Danish Health and Medicine Agency (2015030166), the Committee on Health Research Ethics in the Capital Region of Denmark ( $\mathrm{H}-16036586$; with additional local/national ethics approvals in the participating countries as appropriate), ${ }^{12}$ by the Danish Data Protection Agency (RH2015-3203695) and registered at ClinicalTrials.gov (NCT02467621).

\section{Definitions}

- Overt GI bleeding: one or more of the following: haematemesis; coffee ground emesis; melaena; haematochezia; bloody nasogastric aspirate.

- CIB: overt GI bleeding and at least one of the following criteria within 24 hours of overt Gl bleeding and in the absence of other causes (clinical evaluation):

1. decrease in systolic/diastolic/mean arterial blood pressure of $\geq 20 \mathrm{mmHg}$

2. start of vasopressor or increase in vasopressor dose of $\geq 20 \%$

3. decrease in haemoglobin of $\geq 2 \mathrm{~g} / \mathrm{dL}(1.24 \mathrm{mmol} / \mathrm{L})$

4. transfusion of two or more units of red blood cells (RBCs).

- Earlier CIB: first CIB episode occurring within the first two days in the ICU after randomisation.

- Later CIB: first CIB episode occurring on the third day in the ICU after randomisation or later.

Earlier and later CIB were defined according to the distribution of CIB onset times in the SUP-ICU inception cohort study. ${ }^{2,10}$ Additional variable definitions can be found in the supplement or the SUP-ICU publications. , $^{9,12,13}$

\section{Outcomes}

The primary outcome in this study was the time (number of days) to the first CIB episode.

Additionally, we studied the following secondary outcomes:

1. Vital status 90 days after randomisation

2. Number of days with CIB per patient 
3. Number of days with overt Gl bleeding per patient

4. Oesophago-gastro-duodenoscopy, laparotomy or coiling performed at least once on days with overt Gl bleeding or CIB

5. Number of units of RBCs transfused on days with CIB per patient

6. Number of units of RBCs transfused in the ICU per patient

And the following post-hoc secondary outcomes:

7. Number of patients transfused with one or more units of RBCs on days with $\mathrm{CIB}$

8. Number of patients transfused with one or more units of RBCs in the ICU

9. Number of patients with one or more overt Gl bleeding episodes

Vital status was primarily obtained from regional/national registries, while all other outcomes were registered while patients were in the ICU, including readmissions or transfers to other participating ICUs. ${ }^{9}$

\section{Statistics}

We present baseline data descriptively for all patients stratified by bleeding status (earlier/later/no CIB) and vital status at day 90 (alive/dead). Numerical data are presented as medians with interquartile ranges (IQRs) and categorical data are presented as numbers with percentages.

\section{Primary outcome and associations with baseline variables}

We present the median (IQR) time to CIB in the full trial cohort and in each intervention group. We assessed the associations between baseline variables (including treatment allocation) and time to CIB using Cox proportional hazards models treating death before $\mathrm{CIB}$ as a competing event and thus censoring patients when they died..$^{14}$ Patients who were lost to follow-up for either CIB or mortality or who withdrew consent for further data registration were censored on the last day with available data.

Due to the limited number of CIB events, we conducted a number of different Cox models. In the first model, the association between allocation to pantoprazole (vs placebo) and CIB onset was assessed, while additional models assessed the effect of each additional baseline variable and CIB in turn. ${ }^{10}$ Models were adjusted for treatment allocation and severity of illness using the Simplified Acute Physiology Score (SAPS) $\mathrm{II}^{15}$; the two models assessing these variables were only adjusted for the other variable.

We estimated hazard ratios (HRs) for CIB in the earlier and later periods and assessed possible differences between periods by including an interaction with time (later period - i.e. day three or later - vs earlier period) and the variable assessed in each model using a time transformation function. ${ }^{16}$ Differences between periods are presented as $\mathrm{HRs}$ for the relative change in the later period compared to the earlier period along with $\mathrm{P}$-values for the relative change. 


\section{Secondary outcomes}

Detailed bleeding event characteristics are presented descriptively for all patients and stratified by bleeding status and vital status as described above. Post-hoc, we decided to also present these data for patients without $\mathrm{CIB}$, and to present the number of patients fulfilling each of the four criteria for CIB, in total and stratified by bleeding status and vital status.

\section{Sample size and general considerations}

The sample size was fixed, as per the SUP-ICU trial, ${ }^{9,12,13}$ and we expected approximately $100-120$ patients with $\mathrm{CIB} .{ }^{2,10}$

Two-tailed P-values $<0.05$ and $95 \%$ confidence intervals (Cls) not including 1.00 were considered statistically significant. We performed no corrections for multiple testing as all analyses presented in this study should be considered exploratory and hypothesis-generating. ${ }^{10}$ All analyses were conducted using $\mathrm{R}$ version 3.5.3 (R Core Team, R Foundation for Statistical Computing, Vienna, Austria).

\section{Missing data handling}

We assessed the amount of missing data for all variables. As missingness for SAPS II was $7.6 \%{ }^{9}$ (Table 1), all Cox models were conducted using multiply imputed data ${ }^{17-19}$ according to the protocol. ${ }^{10}$ We generated 50 multiple imputed datasets using chained equations and included all baseline variables, treatment allocation, time to first CIB event and 90-day vital status in the imputation model. Complete case sensitivity analyses were also conducted.

\section{Post-hoc sensitivity analyses}

As the number of CIB events in the earlier period was lower than expected, we decided to conduct additional post-hoc analyses by repeating the Cox models after redefining the earlier and later periods according to the median number of days to the first CIB episode.

\section{Results}

We included all 3291 patients from the SUP-ICU trial who received trial medication and consented to use of data. ${ }^{9}$

Baseline demographic data stratified by $\mathrm{CIB}$ and vital status are presented in Table 1. Patients who either died before day 90 or had earlier CIB were older, and more patients with earlier CIB were admitted to non-university hospitals. There were no major differences in the number of comorbidities or risk factors between strata; however, more patients who developed earlier CIB had shock at randomisation and higher SAPS II, and more patients who developed CIB (regardless of onset) were on renal replacement therapy at randomisation. 


\section{Primary outcome}

In total, $110 / 3291$ (3.3\%) patients experienced CIB; 41/1644 (2.5\%) in the pantoprazole and $69 / 1647(4.2 \%)$ in the placebo group. The median time to first CIB episode was 6 (IQR: 2 - 13) days overall; 6 (IQR: 2 - 11) days in the pantoprazole group and 6 (IQR: 3 - 13) days in the placebo group. The first CIB episode occurred in the earlier period in $28 / 110$ (25.5\%) patients with CIB (Figure 1).

The associations of baseline variables with CIB in the earlier period and the relative change in the later compared to the earlier period are presented in Table 2. In total, 109/3291 (3.3\%) patients were censored for either CIB or mortality before day 90. Higher SAPS II was consistently associated with CIB with a HR (per point increase) of 1.03 (95\% Cl: $1.01-1.05)$ in the earlier period and a $\mathrm{HR}$ of $1.02(95 \% \mathrm{Cl}: 1.01-$ 1.03) in the later period (relative change in HR in the later compared to the earlier period: $0.99,95 \% \mathrm{Cl} 0.96-1.01 ; P=0.37$ ). Admission to a university hospital was the only variable with a significant change in association with $\mathrm{CIB}$ according to time, with a HR of $0.30(95 \% \mathrm{Cl}: 0.14-0.63)$ in the earlier period vs a HR of $0.85(95 \%$ $\mathrm{Cl}: 0.53-1.37$ ) in the later period (relative change in $\mathrm{HR}$ in the later compared to the earlier period: $2.85,95 \% \mathrm{Cl}: 1.18-6.90 ; P=0.020)$.

A number of variables were associated with statistically significant increases or decreases in CIB risk in the later period, including allocation to pantoprazole (HR 0.51, 95\% Cl: 0.32 -0.80); emergency surgical admission (HR 0.48, 95\% Cl: $0.24-$ 0.99 ); medical admission (HR 0.34, 95\% Cl: $0.17-0.69$ ); renal replacement therapy (HR 2.35, 95\% Cl: 1.32 - 4.20); and SOFA score (HR 1.14, 95\% Cl: 1.05 - 1.24 per point increase).

None of these variables were associated with significantly increased or decreased risk in the earlier period or significant relative changes between periods.

\section{Sensitivity analyses}

The complete case sensitivity analyses were consistent with the primary analyses (supplement Table S1), as were most of the post-hoc sensitivity analyses (supplement Table S2).

\section{Secondary outcomes}

The overall 90 -day mortality rate was $30.7 \% ; 47.3 \%$ and $30.2 \%$ in patients with and without CIB, respectively. Detailed bleeding outcomes are presented in Table 3. More patients with CIB were transfused during the ICU stay, and patients with later CIB received more units of RBCs both during the ICU stay and on days with CIB. Additionally, patients with later CIB had more diagnostic or therapeutic procedures performed for CIB.

The number of patients who fulfilled each of the four criteria for CIB is presented in supplement Table S3. 


\section{Discussion}

In this preplanned, exploratory substudy of the SUP-ICU trial, the median time to CIB was 6 (IQR 2 - 13) days, and later CIB was three times as common as earlier CIB. Higher SAPS II was consistently associated with increased risk of CIB, with no difference in the later compared to the earlier period. Admission to a university hospital was associated with lower CIB risk in the earlier period, while this association was significantly different with a relative increase in the later period. Patients with later CIB received more transfusions and had more diagnostic or therapeutic procedures performed for CIB than patients with earlier CIB.

Being admitted to a university hospital was the only variable that significantly differed in the later as compared to the earlier period. A possible explanation for this finding might be that the most complex patients are more frequently admitted to university hospital ICUs, and this group of patients have longer ICU stays. While we adjusted the analysis for SAPS II, differences in case-mix not accounted for by the limited comorbidity data in SAPS II may also explain the finding. Other potential explanations include ICU admission earlier during the course of illness in university hospitals, or that differences in research resources between university and nonuniversity hospitals may have affected screening and randomisation. The increased number of transfusions and procedures in patients with later compared to earlier CIB may be explained to some extent by the former patients surviving longer.

The only variable that was consistently statistically significantly associated with CIB was SAPS II. The two most plausible explanations for the lack of consistent significant findings in the other analyses are the limited number of events in each period and consequent low power (especially the earlier period, which contained fewer events and fewer significant findings than the later period), but it could also be explained by the adjustment for SAPS II, as most other baseline variables are in some way associated with increased severity of illness. Of note, in the primary SUP$I C U$ results, allocation to pantoprazole led to fewer CIB events (relative risk 0.58, $95 \% \mathrm{Cl} 0.40-0.86) .{ }^{9}$ This is consistent with the findings of this substudy, where pantoprazole was associated with significantly decreased CIB in the later period. Although the $\mathrm{Cls}$ for the earlier period and the relative change include no difference, it is interesting that point estimates suggest decreased CIB risk with PPI in both periods, but the largest effect in the later period.

The lower proportion of earlier CIB compared to the SUP-ICU inception cohort study ${ }^{2}$ may be partially explained by the time from ICU admission to randomisation (median 15 (IQR: 5 - 28) and 14 (IQR: 6 - 23) hours in the pantoprazole and placebo groups, respectively). ${ }^{9}$ Some patients may have experienced GI bleeding shortly after ICU admission leading to prescription of pantoprazole and exclusion from the SUP-ICU trial upon screening. The times to CIB in this study are more comparable to

This article is protected by copyright. All rights reserved. 
estimates from a 20-year old RCT, where approximately 1 in 4 patients with CIB had their first CIB episode within five days after randomisation. ${ }^{20}$

\section{Strengths and limitations}

Strengths of this study reflect those of the SUP-ICU trial, ${ }^{9}$ including the large sample size, pragmatic design, high external validity and data quality; our missing data handling strategy; and prepublication of the protocol and statistical analysis plan, ${ }^{10}$ which increases transparency and trustworthiness. ${ }^{21-24}$

The study has a number of limitations too, and the results should be considered exploratory and hypothesis-generating as stated in the protocol. ${ }^{10} \mathrm{First}$, despite the large size of the SUP-ICU trial, the number of CIB events was limited, as expected, which led to lower precision and a risk of not detecting true differences (type 2 errors). However, potential differences in associations in the two time periods that did not reach statistical significance due to low power are probably of limited clinical relevance due to the rarity of CIB. Second, as the SUP-ICU trial only included patients with at least one risk factor for Gl bleeding, the results may not be directly transferable to ICU patients without any of these risk factors. Third, ICUs participating in the SUP-ICU trial may differ from ICUs not participating in how GI bleeding is recognised and treated. Fourth, our analysis strategy was relatively simple, only adjusted for two variables (SAPS II and allocation to pantoprazole), and only assessed time differences according to one point in time. Other adjustment strategies could have been considered, and associations with CIB if not adjusted for SAPS II or use of SUP may be different. However, the rarity of CIB would make more complex models fragile and conducting additional analyses would increase the risk of chance findings (type 1 errors). Fifth, while our definitions of earlier vs later CIB were based on previous research, ${ }^{2}$ the cut-off of two days may be considered somewhat arbitrary. Importantly, though, results were similar in the sensitivity analyses conducted after redefining the time periods. Finally, the assessment of secondary outcomes according to time of first CIB event may be subject to survival bias and a competing risk of death before $\mathrm{CIB}^{25}$, as the most severely ill patients may be more likely to develop CIB, but also more likely die before that happens. We did not account for this in the descriptive presentations of secondary outcome data.

In conclusion, half of all CIB events happened in the first week, and only a quarter of CIB events occurred in the earlier period. Higher SAPS II was consistently associated with increased risk of CIB, and admission to a university hospital was the only variable with a significantly different association in the time periods considered, with a decreased risk in the earlier period and a relatively increased risk in the later period. Patients with later CIB received more transfusions and had more diagnostic or therapeutic procedures performed for CIB than those with earlier CIB.

This article is protected by copyright. All rights reserved. 


\section{References}

1. Cook DJ, Griffith LE, Walter SD, et al. The attributable mortality and length of intensive care unit stay of clinically important gastrointestinal bleeding in critically ill patients. Crit Care. 2001;5:368-375.

2. Krag M, Perner A, Wetterslev J, et al. Prevalence and outcome of gastrointestinal bleeding and use of acid suppressants in acutely ill adult intensive care patients. Intensive Care Med. 2015;41:833-845.

3. Rhodes A, Evans LE, Alhazzani W, et al. Surviving sepsis campaign: international guidelines for management of sepsis and septic shock: 2016. Intensive Care Med. 2017;43:304-377.

4. $\quad$ Cook D, Heyland D, Griffith $L$, et al. Risk factors for clinically important upper gastrointestinal bleeding in patients requiring mechanical ventilation. Crit Care Med. 1999;27:2812-2817.

5. $\quad$ MacLaren R, Reynolds PM, Allen RR. Histamine-2 Receptor

Antagonists vs Proton Pump Inhibitors on Gastrointestinal Tract Hemorrhage and Infectious Complications in the Intensive Care Unit. JAMA Intern Med. 2014;174:564-574.

6. Charlot M, Ahlehoff O, Norgaard ML, et al. Proton-pump inhibitors are associated with increased cardiovascular risk independent of clopidogrel use: a nationwide cohort study. Ann Intern Med. 2010;153:378-386.

7. Barbateskovic M, Marker S, Granholm A, et al. Stress ulcer prophylaxis with proton pump inhibitors or histamin-2 receptor antagonists in adult intensive care patients: a systematic review with meta-analysis and trial sequential analysis. Intensive Care Med. 2019;45:143-158.

8. Mircea N, Jianu E, Constantinescu C, et al. Stress ulcers in intensive care (etiology, symptomatology and therapy). Resuscitation. 1984;12:59-76.

9. Krag M, Marker S, Perner A, et al. Pantoprazole in Patients at Risk for Gastrointestinal Bleeding in the ICU. N Engl J Med. 2018;379:2199-2208.

10. Granholm A, Lange T, Anthon C, et al. Timing of onset of gastrointestinal bleeding in the ICU: Protocol for a preplanned observational study. Acta Anaesthesiol Scand. 2018;62:1165-1170.

11. von Elm E, Altman DG, Egger M, et al. The Strengthening the Reporting of Observational Studies in Epidemiology (STROBE) statement: Guidelines for reporting observational studies. J Clin Epidemiol. 2008;61:344-349.

12. Krag M, Perner A, Wetterslev J, et al. Stress ulcer prophylaxis in the intensive care unit trial: detailed statistical analysis plan. Acta Anaesthesiol Scand. 2017;61:859-868.

13. Krag M, Perner A, Wetterslev J, et al. Stress ulcer prophylaxis with a proton pump inhibitor versus placebo in critically ill patients (SUP-ICU trial): study protocol for a randomised controlled trial. Trials. 2016;17:205.

14. Beyersmann J, Allignol A, Schumacher M. Competing risks and multistate models with R. New York: Springer; 2012. 
15. Le Gall J-R, Lemeshow S, Saulnier F. A new Simplified Acute Physiology Score (SAPS II) based on a European/North American multicenter study. JAMA. 1993;270:2957-2963. [Erratum, JAMA. 1994;271:1321].

16. Therneau T, Crowson C, Atkinson E. Using Time Dependent Covariates and Time Dependent Coefficients in the Cox Model. Available at: https://cran.rproject.org/web/packages/survival/vignettes/timedep.pdf [Last accessed 13 May 2019]

17. Jakobsen JC, Gluud C, Wetterslev J, Winkel P. When and how should multiple imputation be used for handling missing data in randomised clinical trials - a practical guide with flowcharts. BMC Med Res Methodol. 2017;17:162.

18. Marshall A, Altman DG, Holder RL, Royston P. Combining estimates of interest in prognostic modelling studies after multiple imputation: current practice and guidelines. BMC Med Res Methodol. 2009;9:57.

19. Vesin A, Azoulay E, Ruckly S, et al. Reporting and handling missing values in clinical studies in intensive care units. Intensive Care Med. 2013;39:13961404.

20. Cook D, Heyland D, Griffith L, Cook R, Marshall J, Pagliarello J. Risk factors for clinically important upper gastrointestinal bleeding in patients requiring mechanical ventilation. Canadian Critical Care Trials Group. Crit Care Med. 1999;27:2812-2817.

21. Dal-Ré R, loannidis JP, Bracken MB, et al. Making Prospective Registration of Observational Research a Reality. Sci Trans/ Med. 2014;6:224cm1. 22. Thomas L, Peterson ED. The Value of Statistical Analysis Plans in Observational Research. JAMA. 2012;308:773-774.

23. Loder E, Groves T, MacAuley D. Registration of observational studies. BMJ. 2010;340:c950.

24. The PLOS Medicine Editors. Observational studies: getting clear about transparency. PLoS Med. 2014;11:e1001711.

25. Colantuoni E, Scharfstein DO, Wang C, et al. Statistical methods to compare functional outcomes in randomized controlled trials with high mortality.

BMJ. 2018;360:j5748. 


\section{Tables}

Table 1 Baseline characteristics stratified by outcomes

\begin{tabular}{|c|c|c|c|c|c|c|c|}
\hline Variable & $\begin{array}{l}\text { All patients } \\
(n=3291)\end{array}$ & $\begin{array}{l}\text { Earlier CIB } \\
\text { and alive } \\
(n=16)\end{array}$ & $\begin{array}{l}\text { Earlier CIB } \\
\text { and dead }^{a} \\
(n=12)\end{array}$ & $\begin{array}{l}\text { Later CIB } \\
\text { and alive } \\
(n=42)\end{array}$ & $\begin{array}{l}\text { Later CIB } \\
\text { and dead }^{a} \\
(n=40)\end{array}$ & $\begin{array}{l}\text { No CIB and } \\
\text { alive }^{a} \\
(n=2215)\end{array}$ & $\begin{array}{l}\text { No CIB and } \\
\text { dead }^{a} \\
(n=957)\end{array}$ \\
\hline Age (years) & $\begin{array}{l}67.0(56.0- \\
75.0)\end{array}$ & $\begin{array}{l}71.0(54.8- \\
75.2)\end{array}$ & $\begin{array}{l}74.0(66.2- \\
77.8)\end{array}$ & $\begin{array}{l}64.0(57.2- \\
72.0)\end{array}$ & $\begin{array}{l}71.5(64.5- \\
75.2)\end{array}$ & $\begin{array}{l}65.0(52.0- \\
73.0)\end{array}$ & $\begin{array}{l}72.0(64.0- \\
79.0)\end{array}$ \\
\hline $\begin{array}{l}\text { Number of } \\
\text { comorbidities }^{b}\end{array}$ & $\begin{array}{l}0.0(0.0- \\
1.0)\end{array}$ & $\begin{array}{l}0.0(0.0- \\
1.0)\end{array}$ & $\begin{array}{l}1.0(0.0- \\
1.0)\end{array}$ & $\begin{array}{l}0.0(0.0- \\
1.0)\end{array}$ & $\begin{array}{l}0.0(0.0- \\
1.0)\end{array}$ & $\begin{array}{l}0.0(0.0- \\
1.0)\end{array}$ & $\begin{array}{l}0.0(0.0- \\
1.0)\end{array}$ \\
\hline $\begin{array}{l}\text { Chronic lung } \\
\text { disease }^{b}\end{array}$ & $\begin{array}{l}657 \\
(20.0 \%)\end{array}$ & $4(25.0 \%)$ & $6(50.0 \%)$ & $9(21.4 \%)$ & $7(17.5 \%)$ & $371(16.7 \%)$ & $260(27.2 \%)$ \\
\hline 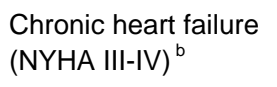 & $199(6.0 \%)$ & $0(0.0 \%)$ & $0(0.0 \%)$ & $2(4.8 \%)$ & $2(5.0 \%)$ & $103(4.7 \%)$ & $91(9.5 \%)$ \\
\hline Immunosuppression $^{\mathrm{b}}$ & $62(1.9 \%)$ & $0(0.0 \%)$ & $0(0.0 \%)$ & $1(2.4 \%)$ & $1(2.5 \%)$ & $35(1.6 \%)$ & 25 (2.6\%) \\
\hline $\begin{array}{l}\text { Haematological } \\
\text { malignancy }^{\mathrm{b}}\end{array}$ & $119(3.6 \%)$ & $1(6.2 \%)$ & $0(0.0 \%)$ & $1(2.4 \%)$ & $4(10.0 \%)$ & $56(2.5 \%)$ & $57(6.0 \%)$ \\
\hline Metastatic cancer ${ }^{b}$ & 111 (3.4\%) & $1(6.2 \%)$ & $1(8.3 \%)$ & $0(0.0 \%)$ & $3(7.5 \%)$ & $46(2.1 \%)$ & $60(6.3 \%)$ \\
\hline $\operatorname{AIDS}^{\mathrm{b}}$ & $7(0.2 \%)$ & $0(0.0 \%)$ & $0(0.0 \%)$ & $0(0.0 \%)$ & $2(5.0 \%)$ & $4(0.2 \%)$ & $1(0.1 \%)$ \\
\hline \multicolumn{8}{|l|}{ Admission type: } \\
\hline - Elective surgical ${ }^{c}$ & $200(6.1 \%)$ & $1(6.2 \%)$ & $0(0.0 \%)$ & $6(14.3 \%)$ & $4(10.0 \%)$ & $139(6.3 \%)$ & $50(5.2 \%)$ \\
\hline $\begin{array}{l}\text { - Emergency } \\
\text { surgical }\end{array}$ & $\begin{array}{l}1048 \\
(31.8 \%)\end{array}$ & $5(31.2 \%)$ & $3(25.0 \%)$ & $16(38.1 \%)$ & $14(35.0 \%)$ & $756(34.1 \%)$ & $249(26.0 \%)$ \\
\hline - Medical & $\begin{array}{l}2043 \\
(62.1 \%)\end{array}$ & $10(62.5 \%)$ & $9(75.0 \%)$ & $20(47.6 \%)$ & $22(55.0 \%)$ & $\begin{array}{l}1320 \\
(59.6 \%)\end{array}$ & $658(68.8 \%)$ \\
\hline $\begin{array}{l}\text { Number of risk } \\
\text { factors }^{d}\end{array}$ & $\begin{array}{l}2.0(2.0- \\
3.0)\end{array}$ & $\begin{array}{l}2.0(1.8- \\
2.0)\end{array}$ & $\begin{array}{l}2.0(2.0- \\
2.2)\end{array}$ & $\begin{array}{l}2.0(1.0- \\
3.0)\end{array}$ & $\begin{array}{l}2.0(2.0- \\
3.2)\end{array}$ & $\begin{array}{l}2.0(2.0- \\
3.0)\end{array}$ & $\begin{array}{l}2.0(2.0- \\
3.0)\end{array}$ \\
\hline $\begin{array}{l}\text { Chronic liver } \\
\text { disease }^{d}\end{array}$ & $94(2.9 \%)$ & $0(0.0 \%)$ & $0(0.0 \%)$ & $1(2.4 \%)$ & $2(5.0 \%)$ & $46(2.1 \%)$ & $43(4.5 \%)$ \\
\hline $\begin{array}{l}\text { Chronic renal } \\
\text { replacement } \\
\text { therapy }^{d}\end{array}$ & $37(1.1 \%)$ & $0(0.0 \%)$ & $0(0.0 \%)$ & $0(0.0 \%)$ & $0(0.0 \%)$ & $19(0.9 \%)$ & $18(1.9 \%)$ \\
\hline Acute coagulopathy $^{d}$ & $\begin{array}{l}577 \\
(17.5 \%)\end{array}$ & $2(12.5 \%)$ & $1(8.3 \%)$ & $6(14.3 \%)$ & $13(32.5 \%)$ & $346(15.6 \%)$ & $209(21.8 \%)$ \\
\hline
\end{tabular}

This article is protected by copyright. All rights reserved. 


\begin{tabular}{|c|c|c|c|c|c|c|c|}
\hline $\begin{array}{l}\text { Use of intravenous } \\
\text { thrombolysis }^{d}\end{array}$ & $47(1.4 \%)$ & $0(0.0 \%)$ & $0(0.0 \%)$ & $0(0.0 \%)$ & $2(5.0 \%)$ & $37(1.7 \%)$ & $8(0.8 \%)$ \\
\hline $\begin{array}{l}\text { Invasive mechanical } \\
\text { ventilation }^{d}\end{array}$ & $\begin{array}{l}2589 \\
(78.7 \%)\end{array}$ & $12(75.0 \%)$ & $9(75.0 \%)$ & $32(76.2 \%)$ & $31(77.5 \%)$ & \begin{tabular}{|l}
1739 \\
$(78.5 \%)$
\end{tabular} & 759 (79.3\%) \\
\hline Shock at inclusion ${ }^{d}$ & \begin{tabular}{|l}
2467 \\
$(75.0 \%)$
\end{tabular} & $14(87.5 \%)$ & $11(91.7 \%)$ & $31(73.8 \%)$ & $35(87.5 \%)$ & \begin{tabular}{|l}
1608 \\
$(72.6 \%)$
\end{tabular} & $762(79.6 \%)$ \\
\hline $\begin{array}{l}\text { Renal replacement } \\
\text { therapy at inclusion }\end{array}$ & 258 (7.8\%) & $3(18.8 \%)$ & $2(16.7 \%)$ & $5(11.9 \%)$ & $10(25.0 \%)$ & 147 (6.6\%) & $91(9.5 \%)$ \\
\hline SAPS $\|^{e}$ & $\begin{array}{l}48.0(38.0- \\
59.0)\end{array}$ & $\begin{array}{l}52.0(41.5- \\
58.0)\end{array}$ & $\begin{array}{l}68.0(60.8- \\
77.0)\end{array}$ & $\begin{array}{l}47.5(36.0- \\
55.2)\end{array}$ & $\begin{array}{l}54.0(47.0- \\
65.5)\end{array}$ & $\begin{array}{l}45.0(36.0- \\
56.0)\end{array}$ & $\begin{array}{l}55.0(45.0- \\
66.0)\end{array}$ \\
\hline SOFA score ${ }^{e}$ & $\begin{array}{l}9.0(7.0- \\
11.0)\end{array}$ & $\begin{array}{l}8.0(6.5- \\
10.0)\end{array}$ & $\begin{array}{l}11.0(9.5- \\
12.2)\end{array}$ & $\begin{array}{l}9.0(6.0- \\
11.0)\end{array}$ & $\begin{array}{l}11.0(9.0- \\
13.0)\end{array}$ & $\begin{array}{l}8.0(6.0- \\
10.0)\end{array}$ & $\begin{array}{l}10.0(7.0- \\
12.0)\end{array}$ \\
\hline $\begin{array}{l}\text { Allocated to } \\
\text { pantoprazole (vs } \\
\text { placebo) }\end{array}$ & $\begin{array}{l}1644 \\
(50.0 \%)\end{array}$ & $7(43.8 \%)$ & $6(50.0 \%)$ & $9(21.4 \%)$ & $19(47.5 \%)$ & \begin{tabular}{|l}
1116 \\
$(50.4 \%)$
\end{tabular} & $485(50.7 \%)$ \\
\hline
\end{tabular}

Baseline data stratified by clinical outcomes. For detailed definitions, see supplement or elsewhere. 9,10,12,13

a Stratified by any CIB episode (earlier/later/none) and vital status 90 days after inclusion. The 9 patients with missing vital status at day 90 are only included in the "All patients" column; none of these patients had CIB.

$\mathrm{b}$ The number of comorbidities includes all comorbidities marked with ${ }^{\mathrm{b}}$.

${ }^{c}$ Only acutely admitted patients were included; elective surgical patients were patients who had elective surgery in the seven days prior to ICU admission and were then acutely admitted to a participating ICU due to complications or events happening after the elective surgery, without fulfilment of the criteria for being classified as acute surgical admission.

${ }^{d}$ The number of risk factors includes all risk factors marked with ${ }^{d}$.

e In total, 249 patients (7.6\%) had missing data for SAPS II and 193 patients (5.9\%) had missing data for the SOFA score. No data were missing for any other baseline variables presented in this table.

Abbreviations: AIDS: acquired immune deficiency syndrome; CIB: clinically important gastrointestinal bleeding; ICU: intensive care unit; NYHA: New York Heart Association functional classification; NSAID: non-steroidal anti-inflammatory drugs; SAPS II: Simplified Acute Physiology Score II; SOFA score: Sequential [Sepsisrelated] Organ Failure Assessment score. 


\section{Table 2 Associations between baseline characteristics and CIB in the earlier and later periods}

\begin{tabular}{|c|c|c|c|c|}
\hline Variable & $\begin{array}{l}\text { Hazard ratio in the } \\
\text { earlier period }(95 \% \\
\text { Cl) }\end{array}$ & $\begin{array}{l}\text { Hazard ratio in the } \\
\text { later period }(95 \% \\
\mathrm{Cl})\end{array}$ & $\begin{array}{l}\text { Relative change in } \\
\text { hazard ratio in the } \\
\text { later compared to } \\
\text { the earlier period } \\
(95 \% \mathrm{Cl})\end{array}$ & $\begin{array}{l}\text { P-value for } \\
\text { test of } \\
\text { change in } \\
\text { association } \\
\text { with time }\end{array}$ \\
\hline $\begin{array}{l}\text { Allocated to pantoprazole } \\
\text { (vs placebo) }\end{array}$ & $0.85(0.40-1.78)$ & $0.51(0.32-0.80)$ & $0.60(0.25-1.42)$ & 0.24 \\
\hline Age (per year) & $1.01(0.98-1.04)$ & $1.01(0.99-1.02)$ & $1.00(0.97-1.03)$ & 0.85 \\
\hline Male gender & $0.85(0.40-1.82)$ & $1.04(0.66-1.64)$ & $1.22(0.50-2.95)$ & 0.66 \\
\hline $\begin{array}{l}\text { Number of comorbidities }{ }^{\mathrm{a}} \\
\text { (per comorbidity) }\end{array}$ & $0.99(0.59-1.69)$ & $1.11(0.82-1.51)$ & $1.12(0.61-2.06)$ & 0.71 \\
\hline $\begin{array}{l}\text { Admitted to university } \\
\text { hospital }\end{array}$ & $0.30(0.14-0.63)$ & $0.85(0.53-1.37)$ & $2.85(1.18-6.90)$ & 0.020 \\
\hline $\begin{array}{l}\text { Time from ICU admission } \\
\text { to randomisation (per } \\
\text { hour) }\end{array}$ & $0.99(0.97-1.01)$ & $1.00(1.00-1.01)$ & $1.01(0.99-1.03)$ & 0.17 \\
\hline \multicolumn{5}{|l|}{$\begin{array}{l}\text { Admission type: } \\
\text { - Reference: elective } \\
\text { surgical }^{\mathrm{b}}\end{array}$} \\
\hline - Emergency surgical & $1.21(0.15-9.73)$ & $0.48(0.24-0.99)$ & $0.40(0.04-3.59)$ & 0.41 \\
\hline - Medical & $1.38(0.18-10.35)$ & $0.34(0.17-0.69)$ & $0.25(0.03-2.08)$ & 0.20 \\
\hline $\begin{array}{l}\text { Number of risk factors }{ }^{\mathrm{C}} \\
\text { (per risk factor) }\end{array}$ & $0.80(0.55-1.16)$ & $1.08(0.88-1.32)$ & $1.36(0.89-2.07)$ & 0.16 \\
\hline Chronic liver disease $^{C}$ & Too few events $^{\dagger}$ & Too few events $^{\dagger}$ & Too few events ${ }^{t}$ & $\begin{array}{l}\text { Too few } \\
\text { events }\end{array}$ \\
\hline $\begin{array}{l}\text { Chronic renal replacement } \\
\text { therapy }{ }^{c}\end{array}$ & Too few events $^{\dagger}$ & Too few events $^{\dagger}$ & Too few events $^{\dagger}$ & $\begin{array}{l}\text { Too few } \\
\text { events }\end{array}$ \\
\hline Acute coagulopathy ${ }^{c}$ & $0.53(0.16-1.76)$ & $1.38(0.83-2.32)$ & $2.61(0.71-9.61)$ & 0.15 \\
\hline History of coagulopathy ${ }^{c}$ & Too few events ${ }^{\dagger}$ & Too few events ${ }^{\dagger}$ & Too few events ${ }^{\dagger}$ & $\begin{array}{l}\text { Too few } \\
\text { events }^{f}\end{array}$ \\
\hline Use of anticoagulants $^{c}$ & $0.54(0.19-1.56)$ & $0.89(0.52-1.52)$ & $1.64(0.50-5.37)$ & 0.41 \\
\hline $\begin{array}{l}\text { Use of NSAID or } \\
\text { acetylsalicylic acid }\end{array}$ & $0.40(0.10-1.69)$ & $0.62(0.31-1.25)$ & $1.55(0.31-7.66)$ & 0.59 \\
\hline $\begin{array}{l}\text { Use of intravenous } \\
\text { thrombolysis }\end{array}$ & Too few events ${ }^{\dagger}$ & Too few events ${ }^{t}$ & Too few events ${ }^{t}$ & $\begin{array}{l}\text { Too few } \\
\text { events }^{f}\end{array}$ \\
\hline $\begin{array}{l}\text { Invasive mechanical } \\
\text { ventilation }^{c}\end{array}$ & $0.70(0.29-1.64)$ & $0.80(0.48-1.34)$ & $1.15(0.42-3.12)$ & 0.78 \\
\hline Shock at inclusion ${ }^{c}$ & $2.50(0.75-8.30)$ & $1.31(0.76-2.27)$ & $0.52(0.14-1.95)$ & 0.34 \\
\hline $\begin{array}{l}\text { Renal replacement } \\
\text { therapy at inclusion }\end{array}$ & $2.18(0.82-5.78)$ & $2.35(1.32-4.20)$ & $1.08(0.35-3.31)$ & 0.89 \\
\hline SAPS II (per point) & $1.03(1.01-1.05)$ & $1.02(1.01-1.03)$ & $0.99(0.96-1.01)$ & 0.37 \\
\hline SOFA score (per point) & $1.06(0.94-1.21)$ & $1.14(1.05-1.24)$ & $1.08(0.94-1.23)$ & 0.28 \\
\hline
\end{tabular}

Associations between baseline variables and CIB according to time. All models assessed the association between each baseline variable and time to CIB in turn using Cox regressions adjusted for treatment allocation (pantoprazole vs placebo) and SAPS II, with an interaction term between the variable and time (specifically, assessing the relative change in association in the later compared to the earlier period).

This article is protected by copyright. All rights reserved. 
${ }^{a}$ Number of comorbidities included the following comorbidities: chronic lung disease; previous myocardial infraction; chronic heart failure (NYHA III-IV); immunosuppression; haematological malignancy; metastatic cancer; and AIDS. ${ }^{\mathrm{b}}$ Only acutely admitted patients were included; elective surgical patients were patients who had elective surgery in the seven days prior to ICU admission and were then acutely admitted to a participating ICU due to complications or events happening after the elective surgery, without fulfilment of the criteria for being classified as acute surgical admissions.

${ }^{c}$ Variables marked ${ }^{\mathrm{C}}$ are included in the number of risk factors.

d "Too few events" indicates that the analysis was not possible as no patients had both the variable and $\mathrm{CIB}$ in the earlier and/or later period.

Abbreviations: AIDS: acquired immune deficiency syndrome; $\mathrm{Cl}$ : confidence interval; CIB: clinically important gastrointestinal bleeding; ICU: intensive care unit; NSAID: non-steroidal anti-inflammatory drugs; NYHA: New York Heart Association functional classification; SAPS II: Simplified Acute Physiology Score II; SOFA score: Sequential [Sepsis-related] Organ Failure Assessment score. 
Table 3 Detailed bleeding outcome characteristics

\begin{tabular}{|c|c|c|c|c|c|c|c|}
\hline Outcome & $\begin{array}{l}\text { All } \\
\text { patients } \\
(n= \\
3291)\end{array}$ & $\begin{array}{l}\text { Earlier } \\
\text { CIB and } \\
\text { alive }^{a}(n= \\
16)\end{array}$ & $\begin{array}{l}\text { Earlier } \\
\text { CIB and } \\
\text { dead }^{\mathrm{a}}(\mathrm{n}= \\
12)\end{array}$ & $\begin{array}{l}\text { Later CIB } \\
{\text { and } \text { alive }^{a}}^{(n=42)}\end{array}$ & $\begin{array}{l}\text { Later CIB } \\
\text { and dead }^{a} \\
(n=40)\end{array}$ & $\begin{array}{l}\text { No CIB } \\
{\text { and } \text { alive }^{a}}^{(n=2215)}\end{array}$ & $\begin{array}{l}\text { No CIB } \\
\text { and dead }^{a} \\
(n=957)\end{array}$ \\
\hline $\begin{array}{l}\text { Number of days with CIB } \\
\text { episodes in each patient }\end{array}$ & $\begin{array}{l}0.0(0.0- \\
0.0)\end{array}$ & $\begin{array}{l}1.0(1.0- \\
2.2)\end{array}$ & $\begin{array}{l}1.0(1.0- \\
1.0)\end{array}$ & $\begin{array}{l}1.0(1.0- \\
2.0)\end{array}$ & $\begin{array}{l}1.0(1.0- \\
3.0)\end{array}$ & NA & NA \\
\hline $\begin{array}{l}\text { Number of days with overt GI } \\
\text { bleeding episodes in each patient }\end{array}$ & $\begin{array}{l}0.0(0.0- \\
0.0)\end{array}$ & $\begin{array}{l}1.5(1.0- \\
3.2)\end{array}$ & $\begin{array}{l}1.0(1.0- \\
1.0)\end{array}$ & $\begin{array}{l}2.0(1.0- \\
3.0)\end{array}$ & $\begin{array}{l}1.0(1.0- \\
4.0)\end{array}$ & $\begin{array}{l}0.0(0.0- \\
0.0)\end{array}$ & $\begin{array}{l}0.0(0.0- \\
0.0)\end{array}$ \\
\hline $\begin{array}{l}\text { Any procedure performed } \\
\text { (oesophago-gastro- } \\
\text { duodenoscopy/laparotomy/coiling) }\end{array}$ & $50(1.5 \%)$ & $5(31.2 \%)$ & $1(8.3 \%)$ & $\begin{array}{l}23 \\
(54.8 \%)\end{array}$ & $19(47.5 \%)$ & $2(0.1 \%)$ & $0(0.0 \%)$ \\
\hline $\begin{array}{l}\text { Number of units of red blood cells } \\
\text { transfused on days with CIB per } \\
\text { patient }\end{array}$ & $\begin{array}{l}0.0(0.0- \\
0.0)\end{array}$ & $\begin{array}{l}1.0(0.0- \\
2.5)\end{array}$ & $\begin{array}{l}1.5(0.0- \\
2.8)\end{array}$ & $\begin{array}{l}2.0(0.0- \\
4.8)\end{array}$ & $\begin{array}{l}2.0(1.0- \\
9.5)\end{array}$ & NA & NA \\
\hline $\begin{array}{l}\text { Number of units of red blood cells } \\
\text { transfused per patient }\end{array}$ & $\begin{array}{l}0.0(0.0- \\
1.0)\end{array}$ & $\begin{array}{l}3.5(0.0- \\
8.0)\end{array}$ & $\begin{array}{l}2.5(0.8- \\
6.2)\end{array}$ & $\begin{array}{l}7.0(2.2- \\
14.0)\end{array}$ & $\begin{array}{l}7.5(2.8- \\
19.2)\end{array}$ & $\begin{array}{l}0.0(0.0- \\
1.0)\end{array}$ & $\begin{array}{l}0.0(0.0- \\
1.0)\end{array}$ \\
\hline $\begin{array}{l}\text { Any red blood cell transfusions on } \\
\text { days with CIB }\end{array}$ & $78(2.4 \%)$ & $8(50.0 \%)$ & $8(66.7 \%)$ & $\begin{array}{l}30 \\
(71.4 \%)\end{array}$ & $32(80.0 \%)$ & NA & NA \\
\hline $\begin{array}{l}\text { Any red blood cell transfusions } \\
\text { during ICU stay }\end{array}$ & $\begin{array}{l}1023 \\
(31.1 \%)\end{array}$ & $10(62.5 \%)$ & $9(75.0 \%)$ & $\begin{array}{l}35 \\
(83.3 \%)\end{array}$ & $36(90.0 \%)$ & $\begin{array}{l}624 \\
(28.2 \%)\end{array}$ & $\begin{array}{l}304 \\
(31.8 \%)\end{array}$ \\
\hline Any overt Gl bleeding episodes & $\begin{array}{l}236 \\
(7.2 \%)\end{array}$ & $\begin{array}{l}16 \\
(100.0 \%)\end{array}$ & $\begin{array}{l}12 \\
(100.0 \%)\end{array}$ & $\begin{array}{l}42 \\
(100.0 \%)\end{array}$ & $\begin{array}{l}40 \\
(100.0 \%)\end{array}$ & $72(3.3 \%)$ & $54(5.6 \%)$ \\
\hline
\end{tabular}

Detailed bleeding outcome characteristics during days in the intensive care unit in the 90 days following inclusion (secondary outcomes). No data were missing for any of the outcome variables presented in this table.

${ }^{a}$ Stratified by any CIB episode (earlier/later/none) and vital status 90 days after inclusion.

The 9 patients with missing vital status at day 90 are only included in the "All patients" column; none of these patients had CIB.

Abbreviations: CIB: clinically important gastrointestinal bleeding; Gl: gastrointestinal; ICU: intensive care unit; NA: not applicable.

This article is protected by copyright. All rights reserved. 


\section{Figure titles and legends}

Figure 1 Time of CIB episodes
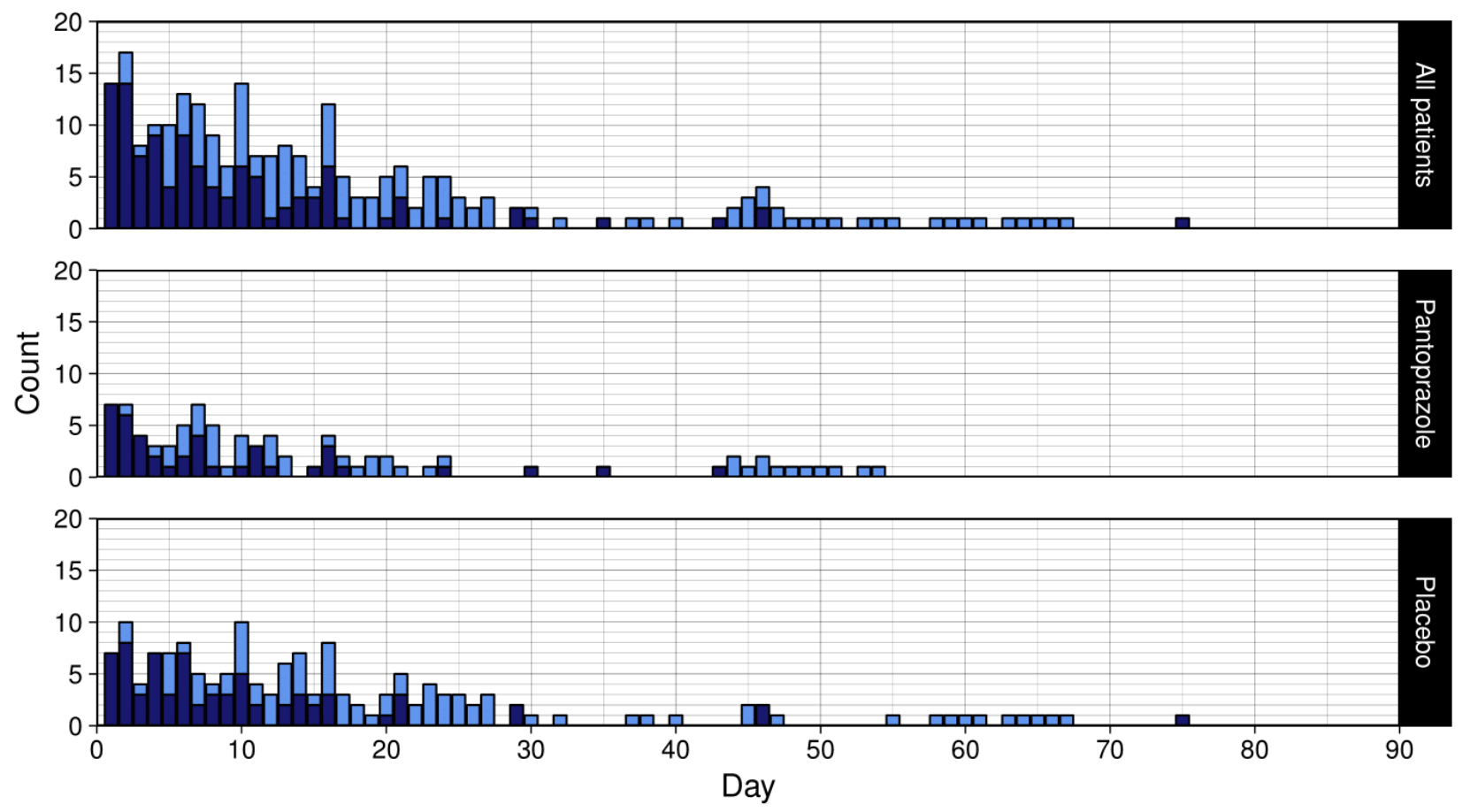

Number of patients with CIB according to days from randomisation in the full trial cohort and stratified by treatment allocation. A similar figure for overt Gl bleeding is presented in the supplement.

The dark part of each bar represents patients who had their first CIB episode on this day, the light part of each bar represents patients who had a CIB episode on this day but previously had another episode.

Abbreviations: CIB: clinically important gastrointestinal bleeding. 